\title{
GESTÃO DE PROJETOS COM O LIFECYCLECANVAS® (LCC): UMA APLICAÇÃO EM UM ÓRGÃO DO PODER LEGISLATIVO
}

\section{PROJECT MANAGEMENT WITH LIFECYCLECANVAS® (LCC): AN APPLICATION IN A LEGISLATIVE BRANCH BODY}

Recebido em: 02 abr. 2020

Aprovado em: 15 nov. 2020

Versão do autor aceita publicada online: 15 nov. 2020

Publicado online: 04 jun. 2021

\section{Como citar esse artigo - American Psychological Association (APA):}

Sousa, B. H. M., \& Medeiros, M. F. M. (2022, jul./set.). Gestão de Projetos com o LifeCycleCanvas® (LCC): uma aplicação em um órgão do poder legislativo. Exacta. 20(3), 727-746.

https://doi.org/10.5585/exactaep.2021.16955.

Submeta seu artigo para este periódico $\bigoplus$

Dados Crossmark 


\title{
GESTÃO DE PROJETOS COM O LIFECYCLECANVAS ${ }^{\circledR}$ (LCC): UMA APLICAÇÃO EM UM ÓRGÃO DO PODER LEGISLATIVO
}

\author{
PROJECT MANAGEMENT WITH LIFECYCLECANVAS ${ }^{\circledR}$ (LCC): AN APPLICATION IN A \\ LEGISLATIVE BRANCH BODY
}

Breno Henrique Medeiros de Sousa ${ }^{1}$

Marcos Fernando Machado de Medeiros ${ }^{2}$

\footnotetext{
${ }^{1}$ Mestre em Gestão Pública - PPGP/UFRN Universidade Federal do Rio Grande do Norte - UFRN. Natal, Rio Grande do Norte - Brasil. brenohmsousa@gmail.com

2 Doutor em Administração - PPGA/UFRN Universidade Federal do Rio Grande do Norte - UFRN Natal, Rio Grande do Norte - Brasil. mfmedeiros@gmail.com
}

Recebido em: 02 abr. 2020

Aprovado em: 15 nov. 2020
Resumo: A administração pública desenvolve-se em um cenário cada vez mais dinâmico, e a demanda por serviços públicos de qualidade reforça a importância de ferramentas de reinvenção às mais diversas estruturas organizacionais. Nesse sentido, a gestão visual de projetos aparece como uma alternativa às práticas tradicionais para contribuir com o incremento dos resultados organizacionais. Este artigo tem por objetivo propor um modelo para simplificar e otimizar a gestão dos projetos estratégicos do poder legislativo do Rio Grande do Norte. Para subsidiar o trabalho, foi realizada uma pesquisa-ação aplicada de natureza qualitativa, através de observação participante e grupo focal. Os resultados obtidos demostraram a aderência do LifeCycleCanvas ${ }^{\circledR}$ (LCC) em relação à gestão do ciclo de vida de um projeto real. Além disso, também foi possível verificar a dinâmica e a gestão da mudança em todas as fases, sendo possível perceber os impactos que afetariam o projeto e promover ajustes. O estudo também gerou implicações gerenciais, como a viabilidade de replicação, com as devidas adaptações, do modelo proposto em outros projetos da Instituição, atuando como ferramenta auxiliar pela Assessoria de Planejamento e abrindo espaço para pesquisas futuras com novas abordagens.

Palavras-chave: Gerenciamento de projetos. Gestão visual. LifeCycleCanvas ${ }^{\circledR}$.

Abstract: Public administration develops in an increasingly dynamic scenario, and the demand for quality public services reinforces the importance of reinvention tools to most diverse organizational structures. In this sense, visual project management appears as an alternative to traditional practices to contribute to the increase of organizational results. This article aims to propose a model to simplify and optimize the management of strategic projects of Rio Grande do Norte State Assembly. To support this work, an applied research-action of qualitative nature was carried out, through participant observation and focus group. The results obtained showed the adherence of the LifeCycleCanvas ${ }^{\circledR}$ LCC in relation to the life cycle management of a real project. In addition, it was also possible to verify the dynamics and management of change in all phases, being possible to perceive the impacts that would affect the project and promote adjustments. The study also generated managerial implications, such as the feasibility of replication, with proper adaptations, of the model proposed in other Institution's projects, acting as an auxiliary tool by planning advisory and opening up space for future research with new approaches.

Keywords: Project Management. Visual management. LifeCycleCanvas ${ }^{\circledR}$. 
1 Introdução

A agenda do Estado tem entre seus princípios a ênfase na prestação de serviços públicos de qualidade (Pimenta, 1998). A demanda por esses serviços em um cenário cada vez mais dinâmico reforça a importância de ferramentas de reinvenção às mais diversas estruturas organizacionais, surgindo assim a reforma gerencial. No entanto, a mera introdução de técnicas da administração privada não é garantia de efetividade no campo da gestão pública, que possui um contexto próprio baseado em cidadania, participação, equidade e transparência, além de temáticas próprias da gestão organizacional contemporânea (Bresser-Pereira, 1996).

Para Kerzner (2002), a estrutura da maioria das organizações é burocrática e lenta, dificultando respostas rápidas a um ambiente em constante mutação. O gerenciamento de projetos aparece como uma alternativa para contribuir com o incremento dos resultados organizacionais. Essas instituições, na busca por alternativas às tradicionais vigentes, adotam mecanismos para apoiar os envolvidos com as práticas de gestão de projetos (Hobbs \& Aubry, 2010). Na esfera pública, entretanto, percebe-se que esse gerenciamento enfrenta diversos desafios (Kossova \& Sheluntcova, 2016), como a complexidade das questões ambientais envolvidas e a variedade de partes interessadas (Patanakul, 2014).

Como alternativa para lidar com a complexidade das organizações atuais, inclusive as públicas, observa-se o surgimento de modelos visuais de gestão de projetos, com a proposta de simplificar e integrar o planejamento por meio de quadros ou telas, também chamados de canvas. Entre os modelos desenvolvidos no Brasil, têm-se como exemplos o Project Model Canvas (Finocchio Júnior, 2013) e o LifeCycleCanvas ${ }^{\circ}$ (Veras, 2016), que proporcionam uma visão integrativa e promovem um maior engajamento e colaboração das partes interessadas, por serem mais flexíveis e de fácil utilização. Este último, ao contrário dos demais modelos, propõe o gerenciamento em todo o ciclo de vida do projeto, trazendo elementos estruturais de modelos considerados tradicionais sem desconsiderar a dinamicidade das ferramentas contemporâneas.

Pretende-se, assim, propor o LifeCycleCanvas ${ }^{\circ}$ (LCC) como mecanismo de gerenciamento de projetos em um órgão público, e testá-lo em um projeto na área de infraestrutura. O projeto adotado como piloto faz parte da política de melhoria e ampliação da estrutura física do Poder Legislativo do Rio Grande do Norte, que inclui a restauração de um imóvel tombado para abrigar um memorial e a construção de um anexo administrativo contíguo, e foi selecionado pela afinidade e familiaridade com as práticas envolvidas, além do realismo envolvido no processo, já que um dos autores integra a equipe que desenvolve os projetos. 


\section{Gestão visual de projetos e o LifeCycleCanvas ${ }^{\circ}$ (LCC)}

A gestão de projetos não é um conceito propriamente novo. Alguns autores defendem que suas práticas existem desde a antiguidade (Lafetá, Barros \& Leal, 2016), enquanto outros apontam para início do século XX, com a aplicação de ferramentas de planejamento (Codas, 1987). Segundo Medeiros et al (2018), uma das correntes mais aceitas é que essas atividades foram concebidas de uma forma mais consolidada, envolvendo projetos de grande porte, entre as décadas de 1950 e 1960. Essa concepção esteve atrelada ao desenvolvimento de projetos no campo da informática e à construção e montagem de obras de grande porte (Codas, 1982).

As práticas de gerenciamento foram disseminadas no decorrer dos anos por meio da sistematização de "guias de conhecimento" (Kolltveit, Karlsen \& Gronhaug, 2007). Esses instrumentos apresentam um conjunto de ações, técnicas e ferramentas para gerir projetos de qualquer natureza, e devido ao surgimento de novos conceitos (como a gestão visual de projetos) são conhecidos como métodos tradicionais (Eder et al., 2015).

No entanto, a natureza do termo evoluiu consideravelmente desde que as "melhores práticas" foram concebidas (Neto \& Resende, 2019), e diversos autores enfatizam a ideia de que essas práticas tradicionais não são adequadas para gerenciar e planejar projetos dentro do contexto atual (Whitty \& Maylor, 2009; Geraldi, Maylor \& Williams, 2011; Whitney \& Daniels, 2013; Lafetá, Barros \& LEAL, 2016), exigindo organizações que procuram gerenciar projetos sob uma base muito mais informal e menos vinculada às disfunções da burocracia (Labuschagne \& Brent, 2005).

Na administração pública, a busca pelo gerenciamento e controle organizacionais reflete a necessidade de minimizar retrabalhos, falhas de comunicação e descoordenação das atividades através, segundo Kerzner (2017), de uma metodologia de gestão de projetos adequada a cada contexto organizacional. O referido autor também ressalta que a metodologia correta melhora a performance durante a execução do projeto e cria condições para o aumento da confiança da sociedade.

$\mathrm{Na}$ tentativa de combater adversidades e minimizar a complexidade dos modelos tradicionais, foram concebidos modelos visuais, conhecidos como telas (em inglês, canvas), a partir de um cenário de inovação. Esses mecanismos, que são mais estruturados e integrados dentro de uma perspectiva diferente dos modelos até então produzidos, tiveram como precursor o Business Model Canvas (BMC), desenvolvido por Yves Pigneur e Alexander Osterwalder (Medeiros \& da Silva, 2017).

No Brasil, alguns modelos de quadros (canvas) têm sido propostos para a gestão de projetos, como o Project Model Canvas (Finocchio Júnior, 2013), o Project Model Mind Map (Mei, 2015), o Project Model Visual (Camargo, 2016) e o LifeCycleCanvas (Veras, 2016). Esses canvas seguem a lógica da ferramenta $5 \mathrm{~W} 2 \mathrm{H}$, um checklist que identifica as rotinas mais importantes de um projeto através de 
cinco perguntas: o quê (what)?, quem (who)?, onde (where)?, quando (when), por quê (why)? Como (how)? e quanto custa (how much)?

O LifeCycleCanvas ${ }^{\circledR}$ (LCC), ao contrário dos demais modelos apontados, demonstra de forma clara as fases distintas de gerenciamento e não rompe com as "melhores práticas", contemplando todas as etapas propostas pelo Guia PMBOK. Seu arcabouço é composto de cinco grandes fases, representadas por telas: iniciação, planejamento, execução, monitoramento/controle e encerramento (Medeiros, Araújo \& Oliveira, 2018), e seu canvas é formado por dois tipos de elementos: informações de interesse do projeto e fatores-chave (Silva Filho, Silva, Silva \& Medeiros, 2018).

O fundamento do modelo é o uso de cores para fatores compostos pela estrutura original do PMC, acrescida dos campos "comunicações" e "aquisições", e representam, na concepção de Veras (2016), as perguntas básicas inerentes a qualquer projeto, dispostas a seguir:

- Por quê? Representa as justificativas, lições aprendidas, benefícios e objetivos de um projeto.

- O quê? Refere-se a três fatores-chave do projeto: produto, requisitos e restrições.

- Quem? Destina-se a explanar partes interessadas, comunicações e equipe do projeto.

- Como? Trata-se dos fatores-chave premissas, entregas e aquisições.

- Quando e quanto? Diz respeito a riscos, custos e tempo.

As telas representam o ciclo de vida do projeto, e são denominadas da seguinte forma: LCC-IN (Iniciação), LCC-PL (Planejamento), LCC-EX/M\&C (Execução/Monitoramento e Controle) e LCC-EN (Encerramento). A finalização de cada tela é representada por um documento de formalização do projeto. Esses documentos, também sugeridos pelo Guia PMBOK ${ }^{\circ}$, são chamados de artefatos e representam as saídas dos grupos de processos de gerenciamento (Veras, 2016). Todavia, no LCC esses artefatos são gerados em um formato menos formal e mais simplificado, visando uma maior flexibilidade ao projeto.

A fase de iniciação compreende o primeiro grupo de gerenciamento, que é instituído por uma necessidade identificada, a partir de um novo projeto ou uma nova fase de um projeto existente (Project Management Institute (PMI), 2017; Medeiros, Araújo \& Oliveira, 2018). O artefato desse grupo é o Termo de Abertura do Projeto (TAP), que representa a autorização formal do patrocinador do projeto para que possa ser planejado. Nesse momento, o processo de integração relativo ao TAP refere-se ao preenchimento inicial dos campos, com ênfase nos três primeiros campos do lado esquerdo.

A tela de planejamento trata dos processos atrelados a um plano de gerenciamento e seus respectivos documentos, especificando todos os passos a serem realizados, inclusive contingências e previsões. Para simplificar a etapa, o LCC propõe agrupar esses processos em 12 campos. A primeira coluna, que trata do "porquê", se mantém inalterada, sendo revisada apenas na fase de encerramento 
(Project Management Institute (PMI), 2017; Medeiros, Araújo \& Oliveira, 2018). Nessa tela, o artefato diz respeito ao Plano de Gerenciamento do Projeto (PGP), e define o trabalho a ser realizado (Medeiros \& Veras et al., 2017).

O método também sugere a realização das etapas de execução e monitoramento e controle simultaneamente (Medeiros \& Veras et al., 2017), em uma única tela. Tal fato ocorre pois os processos relativos a monitoramento e controle acontecem durante a etapa de execução, dando subsídios para a análise de desempenho do projeto. Nessa tela, 10 (dez) fatores podem influenciar o monitoramento e controle. Os campos "tempo" e "custos" são preenchidos automaticamente, os demais através de pesquisa quantitativa com as partes interessadas (Veras, 2016). O Relatório Executivo do Projeto (REP) representa o artefato desta etapa e descreve as entregas do projeto que foram aceitas em determinado momento (Medeiros \& Veras et al., 2017).

A tela de encerramento formaliza a aceitação do produto ou serviço do projeto ou de apenas uma fase deste, e envolve os 15 (quinze) fatores, considerando o final do projeto. Aqui o documento formal configura o Termo de Encerramento do Projeto (TEP). Nele se tem a representação formal do encerramento de um projeto, com as entregas concluídas e validadas, encerramento das aquisições realizadas ao longo do projeto e o registro das principais lições aprendidas (Medeiros, Araújo \& Oliveira, 2018).

Veras (2016) também sugere o uso de seis ferramentas de apoio ao gerenciamento, propostas pelo PMI, e incorporou as dez áreas de conhecimento e os cinco grupos de processos na etapa de planejamento do LCC. Em síntese, o modelo é norteado pelas boas práticas em gestão de projetos, mas, ao mesmo tempo, o tipo de canvas proposto dinamiza os processos de gerenciamento, já que permite que a tela de projetos seja modificada ao longo do ciclo de vida.

\section{Metodologia}

Este artigo pode ser classificado quanto à natureza, à abordagem, aos objetivos e aos procedimentos. Quanto à natureza, configura-se como aplicada, uma vez que pretende gerar conhecimentos que possam ser aplicados de forma prática no gerenciamento dos projetos estratégicos da Assembleia Legislativa do Rio Grande do Norte. No que tange à abordagem, o estudo é qualitativo, pois apresenta o ambiente como fonte direta dos dados (Prodanov \& Freitas, 2013).

Em relação aos objetivos, é possível classificar a pesquisa como exploratório-descritiva. Para Vergara (2014), uma investigação exploratória se dá quando é consumada em área com pouco conhecimento acumulado e sistematizado. Raupp e Beuren (2006) ratificam a afirmação, acrescentando que a pesquisa exploratória se caracteriza pelo aprofundamento de conceitos preliminares não contemplados de maneira suficiente, esclarecendo questões que foram superficialmente exploradas. 
As investigações que tratam de modelos e ferramentas baseadas em canvas para a área de gerenciamento de projetos ainda são incipientes, tendo, portanto, um campo a ser explorado (Medeiros et al., 2017).

Em referência ao caráter descritivo, considera-se adequada a classificação, tendo em vista que o estudo busca descrever as características de determinada população ou fenômeno, estabelecendo correlações entre variáveis (Vergara, 2014), sem que ocorra a manipulação do pesquisador (Andrade, 2008).

Quanto aos procedimentos, foram utilizadas as seguintes técnicas: fontes documentais e pesquisa-ação. Acerca das fontes documentais, o panorama volta-se para o uso de documentos institucionais e detalhes do projeto de infraestrutura objeto deste trabalho. Esse tipo de dado é assim classificado pois apresenta relação direta com os fatos analisados (Richardson, 2017).

A pesquisa-ação acontece quando é elaborada em estreita associação com uma ação ou com a resolução de um problema, no qual os atores implicados participam, junto com os pesquisadores, para chegarem interativamente a elucidar a realidade em que estão inseridos, buscando e experimentando soluções em uma situação real (Xavier Filho, 2018). Simultaneamente, há produção e uso de conhecimento (Thiollent, 1998). O estudo contou com a participação direta de seis colaboradores da instituição, incluindo um dos pesquisadores responsáveis por esta pesquisa.

A materialização das fases ocorreu de maio de 2019 a janeiro de 2020. Todas as informações e análises aqui contidas foram retiradas a partir de discussões realizadas por um grupo focal, consultas à literatura e legislações incidentes, além de dados e documentos coletados como observador participante. O grupo focal consolidou os dados levantados, validou o preenchimento das telas e contou com a participação de seis servidores envolvidos no projeto em questão e foi realizado no dia 28 de novembro de 2019. As observações in loco foram baseadas na experiência dos próprios executantes do processo como diretriz e fonte de informação para a pesquisa.

\section{Análise e discussão dos resultados}

As informações aqui levantadas e consolidadas apresentam a aplicação dos conceitos do LifeCycleCanvas ${ }^{\circ}$ (LCC) durante as etapas iniciais para restauração de um imóvel tombado, que abrigará o Memorial do Legislativo Potiguar, e construção de um prédio anexo integrado, que abrigará o corpo administrativo do Órgão.

Neste cenário, considerando ainda a complexidade e o tempo para realização do projeto, optouse, para garantir sua aplicabilidade, por fragmentá-lo e focar este artigo apenas entrega dos projetos executivos. Essa subdivisão é recomendada pelo PMI (2017), que sugere a subdivisão do projeto em 
partes menores e mais facilmente gerenciáveis, quais sejam, os componentes de cada nível da Estrutura Analítica do Projeto (EAP), resultando em uma definição cada vez mais detalhada (PMI, 2017).

Assim, partiu-se para a construção do Termo de Abertura do Projeto (TAP) da etapa de iniciação. As razões mais comuns para se iniciar um projeto estão, geralmente, associadas a respostas estratégicas a um desafio (Thiry-Cherques, 2004). A justificativa para a realização deste se deve a quatro pontos. 0 primeiro e o segundo apontam respectivamente para um gerenciamento ineficiente do layout do prédio sede e para a fragmentação excessiva da estrutura física. O terceiro ponto foi um Auto de Infração recebido pelo Instituto de Patrimônio Histórico e Artístico Nacional - IPHAN, responsabilizando o Poder Legislativo pelo agravamento do estado de conservação da edificação. Por fim, a quarta justificativa para elaboração dos projetos executivos é que essa atividade é um condicionante legal para a obtenção das licenças nos órgãos fiscalizadores.

Os propósitos apontados neste contexto foram subsidiar os projetos complementares e iniciar no processo de obtenção do alvará de início dos serviços de restauração, reforma e construção. Em relação aos benefícios esperados, o grupo destacou a centralização e melhoria da infraestrutura física e tecnológica; a economia de recursos públicos, já que os prédios alugados seriam devolvidos e o valor investido seria revertido para o próprio órgão; e dois decorrentes de valores históricos e sociais, já que o imóvel em foco pertenceu ao ex-governador Tavares de Lyra, responsável pela construção da primeira sede do Poder Legislativo estadual.

Os produtos estabelecidos foram os projetos executivos de reforma e restauro do Solar Tavares de Lyra, e de construção do anexo administrativo contíguo. Para obter esses produtos, o grupo definiu seis requisitos e cinco restrições, geralmente vinculados ao ordenamento normativo exigido pelos órgãos fiscalizadores.

Na construção de um projeto, um dos "fatores chave" envolve os stakeholders e a necessidade de envolvê-los durante o ciclo (Patanakul, 2014). Isto posto, foram identificadas no terceiro bloco as partes interessadas, os canais de comunicação disponíveis, e as equipes envolvidas.

Para que os produtos fossem entregues conforme os requisitos elencados, foram estabelecidas três premissas: a definição do programa de necessidades; a necessidade de levantamentos arquitetônicos e topográfico georreferenciado; e a inclusão do IPHAN nas decisões relativas ao conjunto arquitetônico. Veras (2016) leciona que o não cumprimento dessas premissas pode gerar riscos ao projeto, também representados no TAP.

Por fim, o grupo definiu quatro entregas, materializadas em relatórios, mapeamentos e projetos arquitetônicos. Seguindo a ideia de que todos esses produtos seriam desenvolvidos com a mão-de-obra interna, o grupo focal estabeleceu os fatores de tempo, custo e aquisições envolvidos. Essas informações da etapa de iniciação, representada pelo TAP do projeto, estão contempladas na Figura 1, a seguir. 
Figura 1

Tela referente ao Termo de Abertura dos Projetos Executivos

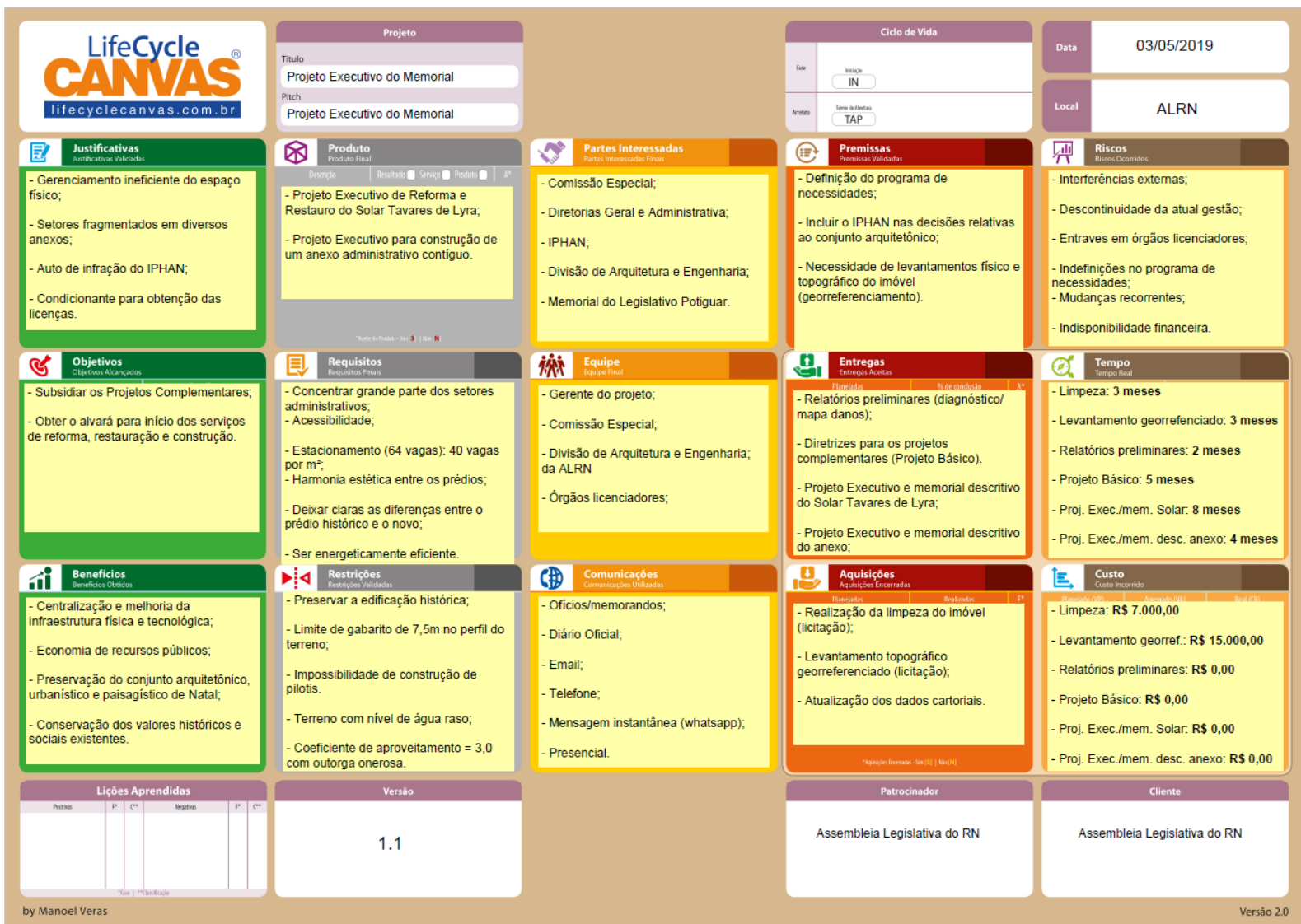

Fonte: Dados da pesquisa, 2019.

Já na etapa de planejamento, a equipe revisou os campos de preenchimento da iniciação e fez uso de planilhas de apoio, recomendadas pelo Guia PMBOK ${ }^{\circ}$ (PMI, 2017), para avaliar pontos importantes das duas metas em foco neste trabalho e construir o artefato PGP (Plano de Gerenciamento de Projeto). Os pontos principais revisados envolveram as partes interessadas, as equipes com suas respectivas entregas, e os riscos envolvidos.

Seguindo as recomendações de Veras (2016), para as partes interessadas, foi empregada uma matriz de engajamento para identificar o grau de envolvimento atual dos stakeholders. O papel de cada componente da equipe durante as atividades ou entregas dos projetos foi revisado através da matriz RACI (ou matriz de responsabilidade), que define com clareza as atribuições, papéis e responsabilidades de cada colaborador nas atividades de um processo. O recurso utilizado para reavaliar os riscos identificados na etapa de iniciação foi a matriz de gerenciamento de riscos.

Dessarte, o grupo entendeu que dois setores de partes interessadas mereciam atenção especial em relação às entregas preestabelecidas: a Divisão de Arquitetura e Engenharia, e o Memorial do Legislativo Potiguar. Em princípio, este último estaria em uma posição neutra de engajamento, 
enquanto aquela acometia-se da seara da Comissão Especial e liderava o processo. Todavia, a recomendação dos participantes era que estes setores atuassem em dando suporte à Comissão. Por esse motivo, ficou estabelecido que o processo de comunicação deveria ser mais efetivo e dinâmico, de forma contínua dos dois setores com a equipe do projeto.

Com a visualização da ferramenta e a partir dos debates gerados por ela, a equipe visulizou que ainda havia uma função sem correspondência na coluna de partes interessadas, com total influência nos rumos do projeto: os setores administrativos que ocuparão o novo anexo. Na revisão do papel de cada um dos integrantes da equipe, procedimento chancelado por Ruiz-Martin e Poza (2015), o grupo focal destacou que o IPHAN é o ponto chave desta etapa, pois pode influenciar nas diretrizes de desenvolvimento, gerando impacto no prazo de conclusão das entregas.

$\mathrm{Na}$ atividade de elaboração da pesquisa histórica e do mapeamento de danos, por exemplo, foi possível entender que, dado o elevado grau de complexidade e dos procedimentos a serem adotados, bem como o tempo disponível, seria necessário envolver um especialista com notório saber na área de restauração de imóveis. A Comissão Especial optou por terceirizar os trabalhos envolvendo a edificação tombada, trabalhando de forma integrada com esse profissional, mas continuou responsável pelo projeto do prédio anexo. Para Vieira (2002), é a perfeita coordenação e integração dos diversos atores envolvidos que garantem o sucesso do projeto.

Na reavaliação dos riscos identificados na etapa de iniciação, foi estabelecida uma escala de variação entre 0,1 e 1,0 para fazer a avaliação de probabilidade e impacto, multiplicando os valores atribuídos em cada uma das colunas. De acordo com o cenário posto, a Comissão decidiu traçar estratégias de resposta aos riscos relacionados, como melhorar a comunicação, mapear competências, justificar tecnicamente as decisões tomadas e verificar a possibilidade de bloqueio orçamentário, como medida de realocação de recursos ou contingenciamento para a natureza da despesa em questão.

Por último, foi visto que no campo referente aos requisitos para os projetos executivos, por tratar-se de um equipamento público e suportar eventuais períodos de falta de recursos para manutenção, poderia ser acrescentado que os materiais especificados devem ser duráveis e de fácil reparo. Com essas novas diretrizes, foi finalizada a tela referente à etapa de planejamento (PGP), representada pela Figura 2 a seguir. 
Figura 2

Tela referente ao Plano de Gerenciamento dos Projetos Executivos

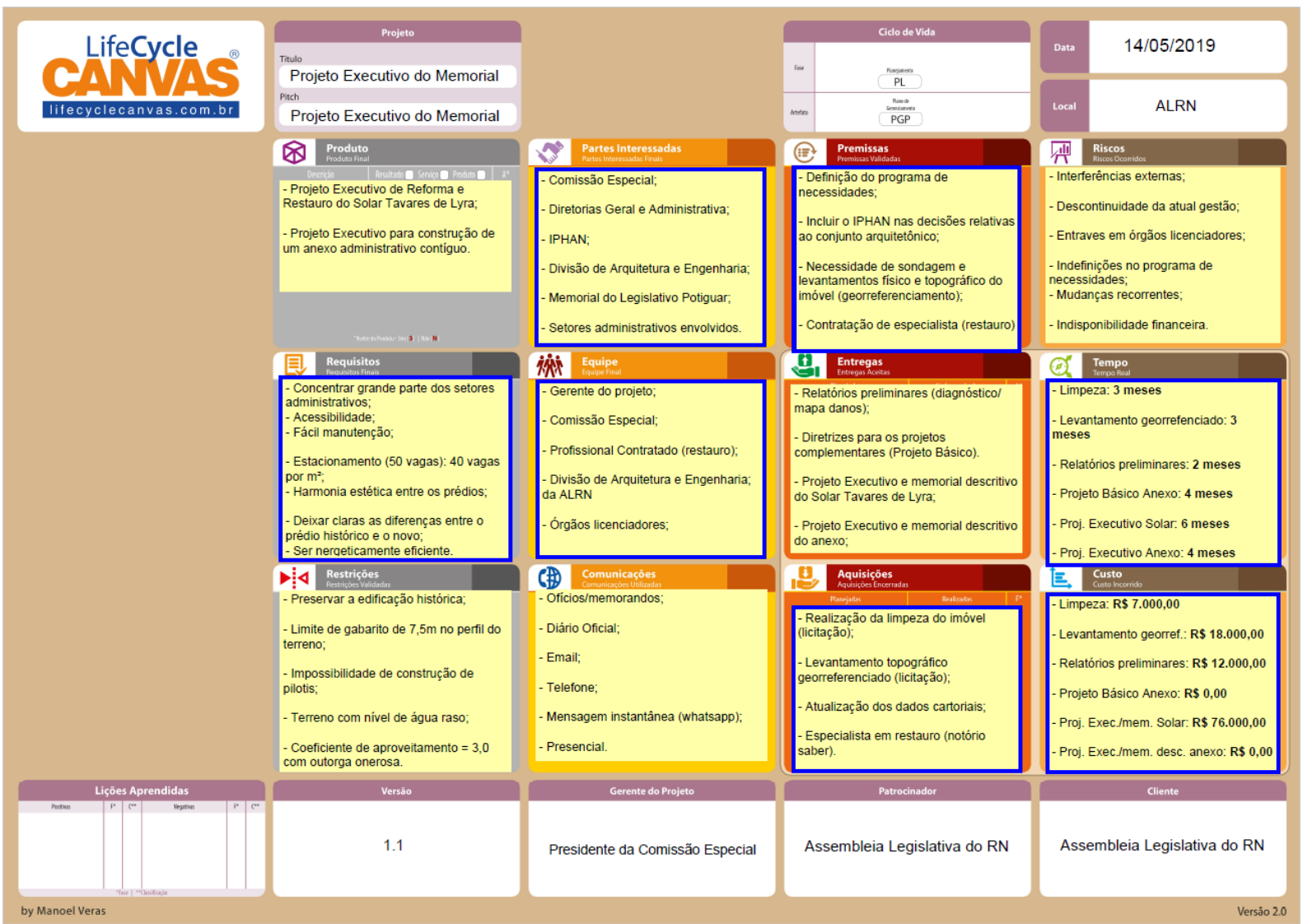

Fonte: Dados da pesquisa, 2019.

Percebe-se que alguns aspectos foram modificados em relação à concepção da etapa de iniciação, em decorrência das análises realizadas durante o PGP, como a inclusão de novos objetos nos campos requisito, partes interessadas, equipe, premissas e aquisições. Com isso, houve uma reavaliação custos do projeto, que passaram para $\mathrm{R} \$ 113.000,00$ (cento e treze mil reais) em decorrência da significativa redução no tempo das entregas, que agora passariam a ser realizadas em apenas oito meses. O aumento se deve à atualização do valor dos serviço de georreferenciamento, que a esta altura já estava sendo contratado, e ao processo de contratação do especialista na área de restauração. Os grupos modificados em relação à fase de iniciação foram contornados com uma borda na cor azul.

Essa decisão resultou em ganho de produtividade, com a redução no tempo final das entregas, além de levantar a discussão acerca de papéis e responsabilidades entre os diversos envolvidos, expondo algumas semelhanças com a pesquisa de Patanakul (2014). Deste modo, o uso da matriz de responsabilidade permitiu uma melhor organização e gestão das atividades do projeto.

O preenchimento dos campos mostrou a flexibilidade do modelo na adaptação das mudanças identificadas, e comprovou a percepção de Medeiros et al. (2018). Por fim, com a integração das áreas 
de gerenciamento e respectivos TGP's, iniciaram-se as discussões para monitoramento das metas. A equipe definiu cinco indicadores de desempenho. Esses índices podem ser contemplados na Figura 3 e são alusivos a tempo, custo, premissas, entregas e aquisições.

\section{Construção dos indicadores dos projetos}

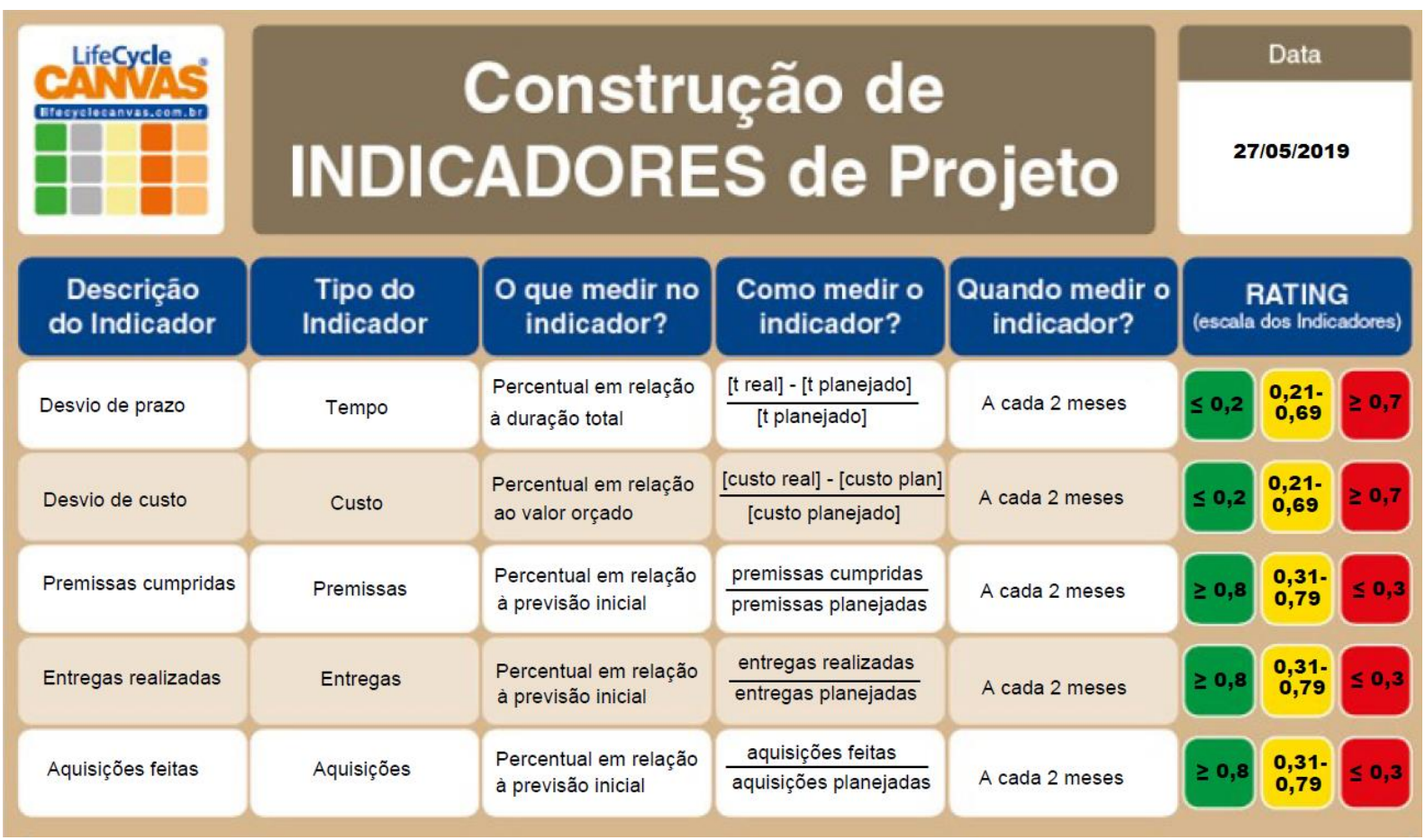

Fonte: Dados da pesquisa, 2019.

Um bom indicador deve englobar características que avaliem o avanço do projeto (Andrade de Souza Neto, Dias, Medeiros, Dantas \& Sousa Neto, 2019). O tempo das entregas foi considerado o indicador de maior relevância, já que atrasos no produto final podem comprometer os resultados estratégicos e inviabilizar todo o projeto. O grupo também definiu que as medições seriam feitas a cada dois meses, a fim de coincidir com o tempo que a Comissão Especial destes projetos tem de prestar contas à Diretoria Administrativa do Órgão. Para a escala de indicadores, foram definidos intervalos para cada artefato, associados às cores verde, amarelo e vermelho.

Durante a fase de execução e monitoramento, representada pelo artefato REP (Relatório Executivo do Projeto), foram realizadas quatro medições para as entregas referentes apenas aos projetos executivos de arquitetura, em consonância com os quatro relatórios bimestrais elaborados pela equipe em junho, agosto, outubro e dezembro de 2019. A definição do rating (escala de indicadores) foi feita conforme recomendação de Veras (2016), em função de cada indicador 
individualmente, e de outro localizado na parte superior da tela, representando o status geral do projeto.

Na primeira medição o órgão havia licitado e contratado os serviços de limpeza do imóvel, e do levantamento topográfico georreferenciado. Neste estágio a empresa contratada finalizou a limpeza e, tendo em vista que o processo licitatório para esses serviços iniciou antes da fase de iniciação, a tarefa foi concluída dois meses antes da data prevista, gerando uma folga no cronograma e um consequente desvio de prazo negativo, medido em 0,67 (1-3/3).

Nesse primeiro mês de execução ainda não foi possível aferir o rating de entregas, mas foram apresentadas as primeiras diretrizes do anteprojeto do prédio anexo, que eram precisamente um diagrama de setorização e acessos, uma planta baixa, uma fachada e uma maquete volumétrica. As providências adotadas proporcionaram, no primeiro Relatório Executivo do Projeto (REP), a contratação de todas as aquisições planejadas para o período, consumando o índice de aquisições feitas para 1, e o índice de premissas cumpridas em 0,5, já que apenas duas das três esperadas, para o tempo medido, haviam sido atingidas.

Esse episódio fez com que o sinal de alerta fosse ligado, levando a equipe a representar o indicador geral do projeto na cor amarela. Como medida corretiva para melhoria do índice, a Comissão cobrou em reunião, aos diretores da Instituição, a definição do programa de necessidades definitivo

Quanto aos custos do projeto, não observou-se nenhum percentual de desvio em nenhuma das quatro medições. Esse objetivo foi atingido em virtude de todos os procedimentos para compras já estarem em andamento na etapa de planejamento, sendo os valores do Termo de Gerenciamento de Projeto (TGP) exatamente iguais aos contratados ou empenhados para contratação. Na concepção de Cheng (2014), uma variação neste campo poderia representar um ponto crítico de falta de controle e monitoramento de custos durante a execução.

Na segunda medição, os fatos principais eram a conclusão do relatório da sondagem do terreno e a apresentação do que já havia sido desenvolvido até o momento ao IPHAN. Os técnicos desta instituição posicionaram-se favoravelmente em relação ao material apresentado, que até este momento não incluía o diagnóstico da edificação com o mapeamento dos danos existentes.

Sem esse complemento, o tempo necessário para realizar todas as entregas previstas aumentou em um mês, resultando em um desvio de prazo de 0,33 (4-3/3), com variação no rating, que passa do verde para o amarelo. Por conseguinte, o índice de entregas realizadas, com o não repasse da única entrega prevista neste período, fechou em 0 nesta aferição, ocasião em que o rating passou a ser vermelho. Pela razão de que esse prazo pode ser compensado em outras etapas, e em decorrência de os outros três índices do canvas apresentarem indicadores na cor verde, o gerente de projetos optou por preencher o indicador geral com a cor amarela. Para melhorar esse índice, foi tomada uma ação de 
conscientização e comprometimento com os prazos acordados. A medida parece ter surtido efeito, já que a entrega foi efetuada no início de setembro.

Os índices de aquisições feitas e o desvio de custo não sofreram variação em relação à primeira tela desta etapa. Ainda no início de setembro, a empresa contratada entregou o georreferenciamento e a poligonal do terreno. A Comissão efetuou os ajustes no projeto, enquanto a empresa contratada trabalha no processo de regularização cartorial, necessária para o licenciamento junto aos órgãos fiscalizadores. Logo, o índice de aquisições passou para 0,75 (3/4) na terceira medição.

Nessa tela, o tempo para entrega dos relatórios preliminares foi atualizado para três meses, e também descontado do tempo para desenvolvimento do projeto executivo de restauração, que passou de seis para cinco meses. A modificação ocorreu para que o prazo final do projeto não fosse alterado e corrigiu o desvio de prazo na aferição anterior, que passou a ser zero, retornando este rating para a cor verde.

Durante a finalização do projeto básico do anexo, os projetistas optaram por uma volumetria de conceitos minimalistas, como estrutura e fachadas limpas de adereços ou itens decorativos, formas geométricas simples com espaços fluidos e superfícies lisas, com predominância de tons neutros e sólidos. Neste sentido, no intuito de dar mais durabilidade, facilitar a manutenção (um dos requisitos do PGP) e vencer os vãos e balanços propostos, adotou-se uma estrutura em concreto armado aparente. Essa solução também contribuiu para a observância de mais dois requisitos previstos: evidenciar as diferenças entre o antigo e o novo; e o uso flexível de marquises e outros elementos de proteção, evitando insolação excessiva nas fachadas e contribuindo com a eficiência energética do prédio

Isto posto, na terceira medição os indicadores referentes a entregas e premissas apresentaram resultados igual a 1, já que todas as premissas previstas foram cumpridas, assim como as duas entregas previstas nesse prazo foram feitas. Conforme a previsão da equipe, o indicador de preço não variou em relação às duas telas anteriores e o indicador geral do projeto melhorou, sendo pela primeira vez representado pela cor verde.

Na quarta e última verificação dos indicadores de monitoramento, representada pela Figura 4 a seguir, as duas frentes de trabalho venceram a etapa dos projetos básicos de arquitetura e avançaram nas especificações técnicas e compatibilizações para conclusão dos projetos executivos. 
Figura 4

Tela referente à execução do projeto com os indicadores do último monitoramento

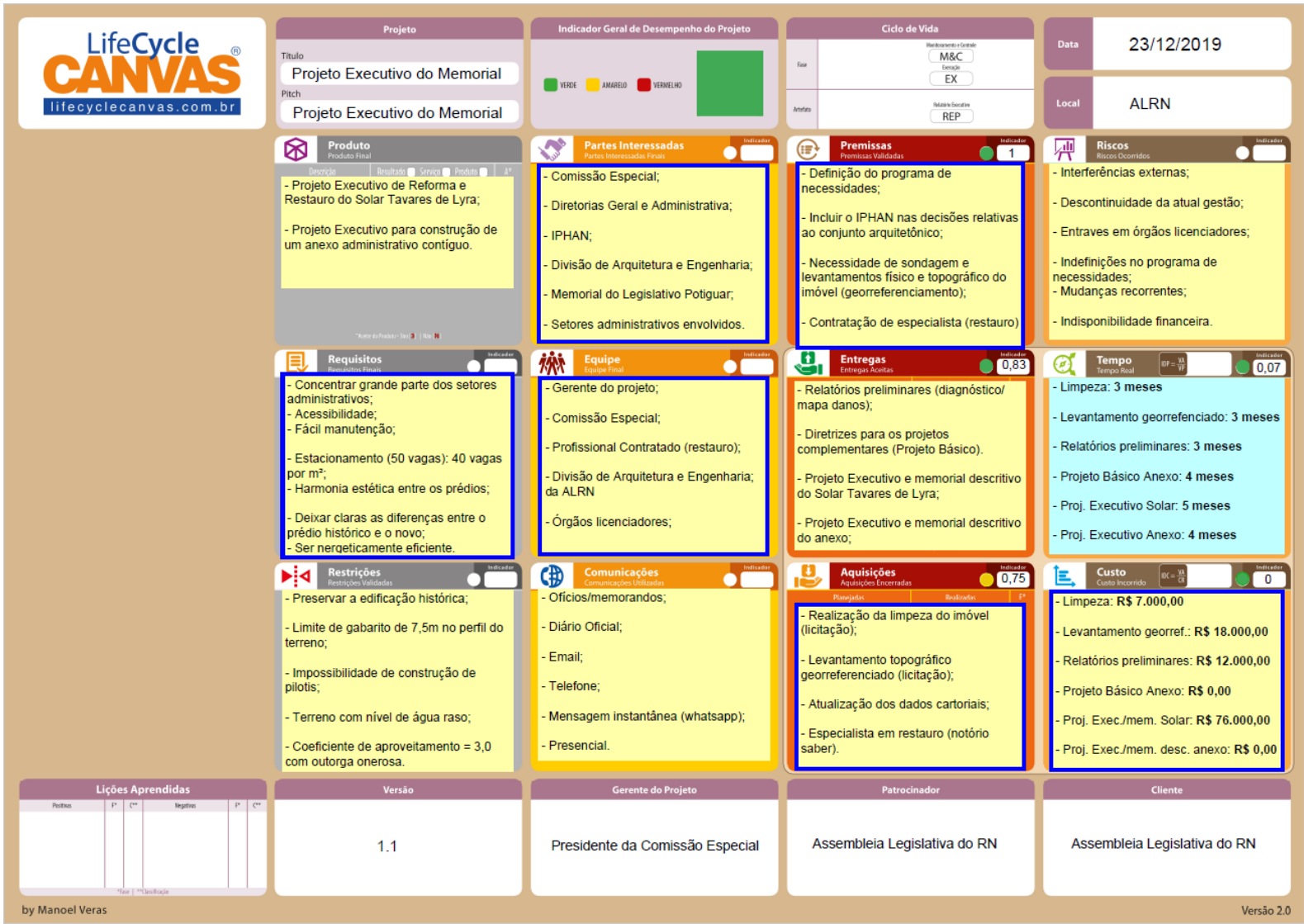

Fonte: Dados da pesquisa, 2019.

Nesse contexto, o índice de aquisições feitas permaneceu em 0,75, já que a empresa responsável pela atualização dos dados cartoriais solicitou prorrogação do prazo de entrega até janeiro de 2020. Com isso, manteve-se a situação de três aquisições concluídas, das quatro previstas. No momento desta última parcial, foram concluídos o mapa de danos e os projetos. As equipes trabalhavam na conclusão dos memoriais descritivos e especificações técnicas, que até esta etapa estima-se que estavam $50 \%$ concluídos. Sendo assim, para facilitar o cálculo dos indicadores, subdividiuse duas entregas em quatro, totalizando seis. Dessas, cinco $(1+1+1+1+0,5+0,5)$ estão concluídas e representam um índice de entregas realizadas igual a 0,83 (5/6).

Como consequência, o tempo efetivamente gasto para as entregas até aqui concluídas foi de sete meses e meio, que quando confrontado com os sete meses previstos gera um desvio de prazo de 0,07 (7,5-7/7). Já o indicador de custo, conforme destaque efetuado na explanação da primeira tela de monitoramento, seguiu sem variação, e a variável geral do projeto seguiu representado pela cor verde.

A formalização das entregas do projeto foi feita através de diligência feita no Instituto do Patrimônio Histórico e Artístico Nacional (IPHAN), realizada no dia 10 de janeiro de 2020, quando foram 
solicitados os formulários para obtenção da aprovação deste órgão e liberação do projeto para as etapas seguintes. Por fim, procedeu-se à etapa de enceramento do projeto, que serviu para registrar o que de fato ocorreu durante todo o projeto, registrar as alterações realizadas, verificar se justificativas, objetivos e benefícios foram atingidos, conforme recomenda o PMI (2017). No entanto, diferente do que recomenda o Guia PMBOK' ${ }^{\circ}$, em que grupos de processos se relacionam durante um projeto, Veras (2016) propõe uma estrutura com fases de gerenciamento sequenciadas, o que facilitou a compreensão da toda a estrutura do projeto por parte dos participantes da pesquisa.

Na Figura 5, pode-se observar que os "post-its" na cor azul representam os fatores que sofreram alterações ao longo do projeto, quando comparados à iniciação. É possível perceber que parte da estrutura do projeto foi modificada para que as entregas previstas fossem viabilizadas e entregues, como requisitos, partes interessadas, equipe, premissas, aquisições, tempo e custo.

Tela referente ao Termo de Encerramento do Projeto

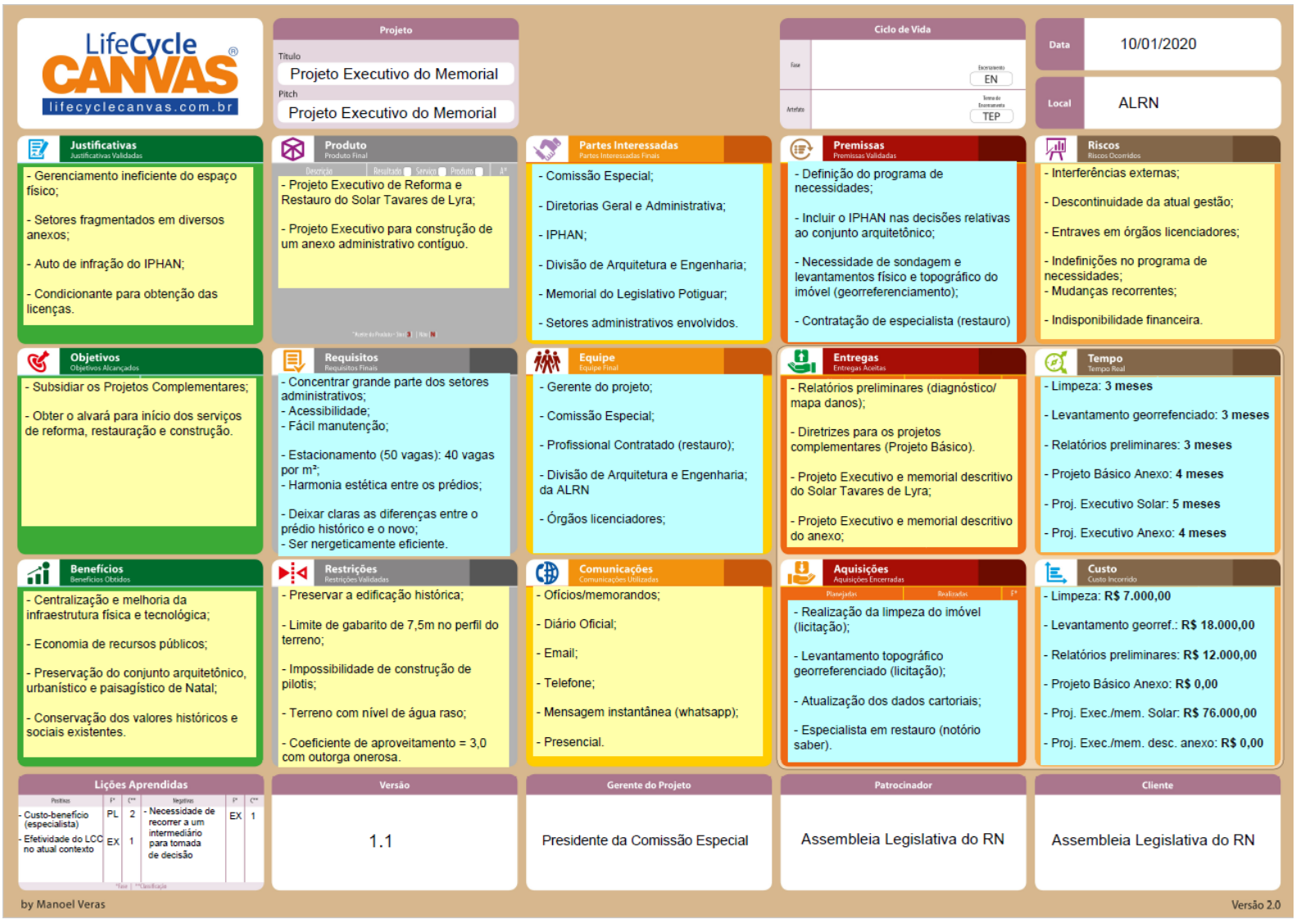

Fonte: Dados da pesquisa, 2019.

Com a conclusão desta etapa, a gestão dos projetos executivos foi realizada em todo o seu ciclo de vida com os fundamentos do LCC, que propõe telas "enxutas" e decisões rápidas e objetivas (Veras, 
2016). Nesse sentido, a lógica de gerenciamento do modelo aplicado propõe uma estrutura com fases de gerenciamento sequenciadas, modificando a estrutura de gerenciamento tradicional, em que processos e rotinas relacionam-se ao longo do ciclo de vida.

\section{Considerações finais}

Este trabalho teve como objetivo testar o LCC como metodologia norteadora para simplificar o monitoramento das metas estratégicas da Assembleia Legislativa do Rio Grande do Norte. Para tanto, foram analisados os diversos processos que compuseram a elaboração de Projetos Arquitetônicos para restauração de um imóvel tombado, e construção de um prédio anexo integrado, no qual abrigará o corpo administrativo da ALRN.

A opção pelo LCC foi feita por se tratar de um modelo visual que permite uma visão integrativa do projeto em todo o ciclo de vida, em um ambiente onde o grau de maturidade sobre o tema ainda é incipiente, e que não prescinde de técnicas outrora utilizadas. Os resultados obtidos puderam verificar essa aderência em relação à gestão do ciclo de vida do projeto estudado. Além disso, também foi possível verificar a dinâmica e a gestão da mudança, com as alterações feitas em todo o ciclo de vida do projeto, sendo possível perceber os impactos que um fator teria sobre o outro e, assim, promover ajustes. Com a construção dos indicadores de desempenho, por exemplo, foi possível a redefinição de estratégias, como a ação de mobilização do colaborador externo à instituição, para que o prazo definido na etapa de iniciação fosse cumprido.

As referidas mudanças estão associadas às ferramentas de apoio utilizadas na fase de planejamento, nas quais estabeleceram estratégias e ações de engajamento com as partes interessadas. Com o preenchimento das telas, a equipe visualizou com clareza requisitos, premissas e entregas, proporcionando uma melhor compreensão das aquisições a serem feitas, balizando a relação custobenefício.

A utilização das telas trouxe uma visão integrada e permitiu a identificação de grupos distintos que precisavam ser envolvidos no processo. As matrizes de engajamento e a definição da forma de comunicação entre as equipes também foram ferramentas importantes para uma melhor compreensão do papel de cada um no projeto.

A utilização da matriz $\mathrm{RACl}$, na fase de planejamento, também permitiu uma melhor organização e gestão das atividades do projeto. Nesse contexto, a contratação de um especialista para desenvolver o projeto de restauração resultou em ganho de produtividade, com redução no tempo final das entregas, além de levantar a discussão acerca de papéis e responsabilidades entre os envolvidos.

Entre as vantagens da metodologia proposta estão a possibilidade de ser utilizada como ferramenta auxiliar pela Assessoria de Planejamento da Instituição, sem descartar as práticas do sistema 
atual utilizado pela Instituição, em um modelo simplificado e, ao mesmo tempo, dinâmico; e o apelo visual característico desse tipo de ferramenta. Apesar disso, ressalta-se que o modelo aqui proposto não possui caráter pronto, estático, pelo contrário, deve evoluir conforme for sendo aplicado em outros projetos.

Ressalte-se, ainda, que o estudo limitou-se a associar os aspectos da gestão de projetos recomendados por Veras (2016), que são associados ao Guia PMBOK, não considerando outras técnicas difundidas e aceitas pelas melhores práticas. Em projetos que adotem essas técnicas, os modelos podem oferecer outras características associadas a este tipo de realidade que não foram aqui analisadas. Pesquisas futuras podem levar esse tipo de análise.

Por fim, outra limitação do trabalho a ser explorada em novos estudos refere-se a um aspecto inerente ao contexto do setor público, mais especificamente os processos de contratação das aquisições, no qual, nesta pesquisa, não se chegou a definir de forma clara como seriam realizados, ficando a cargo da Divisão de Licitações e Contratos.

\section{Referências}

Andrade, M. M. (2008). Como preparar trabalhos para cursos de pós-graduação: noções práticas (7 ed.). São Paulo: Atlas.

Andrade de Souza Neto, R., Dias, G., Medeiros, M., Dantas, A., \& Sousa Neto, M. (2019). Definindo indicadores de desempenho em projetos: uma análise qualitativa da literatura. Exacta, 17(3), 131-148. Disponível em: https://periodicos.uninove.br/exacta/article/view/8203

Bresser-Pereira, L. C. (janeiro-abril, de 1996). Da administração pública burocrática à gerencial. Revista do Serviço Público, 120(47 (1)). Disponível em: https://doi.org/10.21874/rsp.v47i1.702

Camargo, R. (2016). PM Visual (Project Model Visual): gestão de projetos simples e eficaz. São Paulo: Saraiva.

Cheng, Y. M. (2014). An Exploration Into CostInfluencing Factors on Construction Projects. International Journal of Project Management, v. 32, n. 5, p. 850-860. Disponível em: https://doi.org/10.1016/j.ijproman.2013.10.003

Codas, M. B. (1982). Aplicaciones de la gerencia de proyectos. Anales del I Simposio sobre Administración de Proyectos y Gerencia de Obras, Asunción.

Codas, M. B. (jan./mar. de 1987). Gerência de projetos - uma reflexão histórica. Revista de Administração de Empresas, 27(1), 33-37. Disponível em: https://doi.org/10.1590/S003475901987000100004

Eder, S., Conforto, E. C., Amaral, D. C., \& Silva, S. (set. de 2015). Diferenciando as abordagens tradicional e ágil de gerenciamento de projetos. Production, 25(3), 482-497. Disponível em: https://doi.org/10.1590/S0103-65132014005000021 
Finocchio Júnior, J. (2013). Project Model Canvas: gerenciamento de projetos sem burocracia. Rio de Janeiro: Elsevier/Campus.

Gloria Júnior, I., \& Gonçalves, R. F. (2016). As barreiras e motivações para o uso da abordagem canvas. XXXVI ENEGEP, João Pessoa. Disponível em: http://www.abepro.org.br/biblioteca/TN_WPG_230_343_29126.pdf

Hobbs, B., \& Aubry, M. (2010). The Projetc Management Office (PMO): a quest for understanding. Newtown Square: Project Management Institute (PMI).

Kerzner, H. (2002). Gestão de Projetos: as melhores práticas. Porto Alegre: Bookman.

Kerzner, H. (2017). Gestão de Projetos - As Melhores Práticas (3 ed.). Porto Alegre: Bookman.

Kolltveit, B., Karlsen, J., \& Gronhaug, K. (2007). Perspectives on project management. International Journal of Project Management, 25(1), 3-9. Disponível em: https://doi.org/10.1016/j.ijproman.2005.12.002

Kooiman, J. (1993). Modern governance: new government-society interactions. Newbury Park, Calif.: Sage.

Kossova, T., \& Sheluntcova, M. (2016). Evaluating performance of public sector projects in Russia: The choice of a social discount rate. International Journal of Project Management, pp. 403-411. Disponível em: https://doi.org/10.1016/j.ijproman.2015.11.005

Labuschagne, C., \& Brent, A. (fev. de 2005). Sustainable Project life cycle management: the need to integrate life cycles in the manufacturing sector. International Journal of Project Management, 23(2), 159-168. Disponível em: https://doi.org/10.1016/j.ijproman.2004.06.003

Lafetá, F. G., Barros, C. O., \& Leal, P. C. (jan./abr. de 2016). Projetos complexos: estudo de caso sobre a complexidade dos projetos de engenharia de telecomunicações em uma empresa do setor de óleo e gás. Revista de Gestão e Projetos, 7(1), 41-55. Disponível em: https://doi.org/10.5585/gep.v7i1.382

Medeiros, B. C., \& Da Silva, R. R. (2017). Gestão Visual em Projetos: Analisando os modelos de canvas à luz do Guia PMBOK ${ }^{\circledR}$. Simpósio Internacional de Gestão de Projetos, Inovação e Sustentabilidade, 6. Anais, São Paulo: Uninove. Disponível em: https://singep.org.br/6singep/resultado/131.pdf

Medeiros, B. C., Araújo, V. d., \& Oliveira, M. d. (mai. de 2018). Life Cycle Canvas (LCC): Um Modelo Visual para a Gestão do Ciclo de Vida do Projeto. Revista de Gestão e Projetos - GeP, 9(1), 87101. Disponível em: https://periodicos.uninove.br/gep/article/view/9684/4429

Medeiros, B. C., de Sousa Neto, M. V., dos Santos Nobre, A. C., \& Nogueira, G. M. (2017). Planejando projetos com o Life Cycle Canvas (LCC): um estudo sobre um projeto de infraestrutura pública estadual. Exacta, 155-170. Disponível em: https://periodicos.uninove.br/exacta/article/view/6947

Mei, P. (2015). PM Mind Map: a gestão descomplicada de projetos. Rio de Janeiro: Brasport. 
Neto, W., \& Resende, A. (2019). Gerenciamento ágil de projetos em uma empresa Júnior. Exacta, 17(2), 95-104. Disponível em: https://doi.org/10.5585/ExactaEP.v17n2.7860

Patanakul, P. (2014). Managing large-scale IS/IT projects in the public sector: Problems and causes leading to poor performance. The Journal of High Technology Management Research, pp. 2135. Disponível em: https://doi.org/10.1016/j.hitech.2013.12.004

Pimenta, C. C. (1998). A reforma gerencial do Estado brasileiro no contexto das grandes tendências mundiais. In: Reunião de Especialistas do Programa das Nações Unidas em Administração Pública e Finanças. Anais, Nova lorque. Disponível em: http://www.spell.org.br/documentos/ver/13118/a-reforma-gerencial-doestado-brasileiro-nocontexto-das-grandes-tendencias-mundiais/i/pt-br

Prodanov, C. C., \& Freitas, E. C. (2013). Metodologia do trabalho científico: métodos e técnicas da pesquisa e do trabalho acadêmico (2 ed.). Novo Hamburgo: Feevale.

Project Management Institute (PMI). (2017). PMBOK - Guia do conhecimento em gerenciamento (6 ed.). Newton Square: PMI.

Raupp, F. M., \& Beuren, I. M. (2006). Metodologia da pesquisa aplicável às ciências sociais. Em I. M. Beuren, Como elaborar trabalhos monográficos em contabilidade: teoria e prática (3 ed., pp. 76-97). São Paulo: Atlas.

Richardson, R. J. (2017). Pesquisa social: métodos e técnicas (4 ed.). São Paulo: Atlas.

Rio Grande do Norte. (2006). Constituição do Estado do Rio Grande do Norte: promulgada em 3 de outubro de 1989. Natal: Procuradoria-Geral do Estado.

Ruiz-Martin, C., \& Poza, D. J. (2015). Project configuration by means of network theory. International Journal of Project Management, 33(8), 1755-1767. Disponível em: https://doi.org/10.1016/j.ijproman.2015.07.010

Silva Filho, A., Silva, R., Silva, D., \& Medeiros, M. (2018). O processo empreendedor: associando o business model Canvas (BMC) ao life cycle Canvas (LCC). Exacta, 16(4), 35-44. Disponível em: https://doi.org/10.5585/exactaep.v16n4.7991

Thiollent, M. (1998). Metodologia da pesquisa-ação (8 ed.). São Paulo: Cortez.

Thiry-Cherques, H. R. (2004). Modelagem de projetos (2 ed.). São Paulo:Atlas.

Universidade Federal do Rio Grande do Norte. (2018). Resolução nº 02/2018. Colegiado do Programa de Pós-Graduação em Gestão Pública, Natal. Disponível em:

https://sigaa.ufrn.br/sigaa/public/programa/documentos.jsf?lc=pt_BR\&id=5679

Veras, M. (2016). Gestão Dinâmica de Projetos: LifeCycleCanvas ${ }^{\circledR}$. Rio de Janeiro: Brasport.

Vieira, M. M. PMI e a Construção Civil. PMI-RS Journal, n. 2, p. 10-13, 2002.

Vergara, S. C. (2014). Projetos e relatórios de pesquisa em administração (15 ed.). São Paulo: Atlas. 
Whitney, K. M., \& Daniels, C. B. (2013). The root cause of failure in complex IT projects: complexity itself. Procedia Computer Science, 20, 325-330. Disponível em:

https://doi.org/10.1016/j.procs.2013.09.280

Whitty, S. J., \& Maylor, H. (abr. de 2009). And then came Complex Project Management. International Journal of Project Management, 27(3). Disponível em:

https://doi.org/10.1016/j.ijproman.2008.03.004

Xavier Filho, J. (2018). Desenvolvendo Tecnologia de Gestão via Pesquisa-Ação: Uma forma alternativa de demonstrar o Resultado Operacional no Custeio Variável. Exacta, 16(4), 19-34. Disponível em: https://doi.org/10.5585/exactaep.v16n4.7337 